\title{
A Gestão Estadual e a Visibilidade dos Pontos de Cultura Instalados em Boa Vista
}

\author{
La Gestión Estatal y la Visibilidad de los Puntos de Cultura Instalados en \\ Boa Vista
}

\section{The State Management and Visibility of Culture Points installed in Boa Vista}

Jordana de Souza Cavalcante ${ }^{1}$

\begin{abstract}
Resumo
Os Pontos de Cultura são iniciativas conveniadas pelo Governo Federal, por meio do Ministério da Cultura (MinC), em parceria com Governos Estaduais e Municipais de diversos estados brasileiros. Funcionam como verdadeiros polos culturais, desenvolvendo e ofertando à comunidade diversas atividades artísticas que contribuem para o desenvolvimento sociocultural daquela determinada localidade que integra. $\mathrm{O}$ artigo tem por objetivo analisar a gestão estadual de cultura e a visibilidade dos pontos de cultura instalados em Boa Vista. Tendo em vista a relevância social dessas entidades, esta pesquisa, classificada como qualitativa contou, por meio de entrevistas abertas, com a participação dos mais diversos personagens envolvidos neste tema, como o Governo do Estado, responsável pela coordenação de dez Pontos de Cultura que integram a Rede, em Roraima, com representantes dos próprios Pontos, instalados em Boa Vista, assim como com jornalistas da área cultural, na intenção de discutir desafios e dificuldades em promover a visibilidade das ações desenvolvidas por estes grupos, fator que prejudica a legitimidade do trabalho proposto. Foi realizada ainda uma análise anual das editorias de Cultura e Entretenimento de um dos veículos de comunicação de maior relevância em Roraima, o Jornal Folha de Boa Vista, onde foi possível constatar uma notoriedade limitada dos Pontos de Cultura, retratando o descaso com a produção cultural local, por parte do Governo Estadual, o que compromete o desenvolvimento cultural de Roraima, em maior proporção.
\end{abstract}

Palavras Chave: Cultura; Pontos de Cultura; Visibilidade; Identidade.

\section{Resumen}

Puntos de Cultura están conveniadas iniciativas delGobierno Federal, a través delMinisterio de Cultura (Ministerio de Cultura), encolaboraciónconlosgobiernosestatales y municipales de varios estados. Funcionan como verdaderos centros culturales, desarrollar y ofrecer a lacomunidad una variedad de actividades artísticas que contribuyen al desarrollosocio-cultural de esalocalidaden particular que integra. Dada laimportancia social de estas entidades, esta investigación se clasifica como cualitativa contada a través de entrevistas abiertas, conlaparticipación de diversos personajes involucrados en este tema, ya que elGobiernodel Estado, responsable de lacoordinación de diezPuntos de Cultura que se integranreden Roraima, con representantes de puntospropios instalados en Boa Vista, así como periodistas del área cultural, conlaintención de discutir losdesafíos y dificultadesenlapromoción de lavisibilidad de lasaccionesllevadas a cabo por estos grupos, unfactor que socava lalegitimidaddeltrabajopropuesto. También se llevó a cabo una revisión anual de la Cultura y editorial Entretenimiento uno de losmedios de comunicación más relevantes en Roraima, la Folha de Boa Vista, donde era posibleunconocimiento limitado de losPuntos de Cultura, que representa el abandono de laproducción cultural otro por elGobiernodel Estado, lo que socava eldesarrollo cultural de Roraima, enmayorproporción.

Palabras clave: Cultura; Puntos de Cultura; visibilidad; Identidad.

\begin{abstract}
Culture Points are conveniadas initiatives by the Federal Government, through the Ministry of Culture (Ministry of Culture), in partnership with state and municipal governments of several states. They act as true cultural centers, developing and offering the community a variety of artistic activities that contribute to the socio-cultural
\end{abstract}

\footnotetext{
${ }^{1}$ Centro Universitário Estácio da Amazônia, jordanascavalcante@gmail.com
} 
development of that particular locality integrating. Given the social relevance of these entities, this research is classified as qualitative told through open interviews, with the participation of various characters involved in this issue, as the State Government, responsible for coordinating ten Points of Culture that integrate Network in Roraima, with representatives of own points installed in Boa Vista, as well as journalists from the cultural area, intending to discuss challenges and difficulties in promoting the visibility of actions carried out by these groups, a factor that undermines the legitimacy of the work proposed. It was also carried out an annual review of editorial Culture and Entertainment one of the most relevant media outlets in Roraima, the Folha de Boa Vista, where it was possible to a limited awareness of the Culture Points, depicting the neglect of cultural production place by the State Government, which undermines the cultural development of Roraima, in greater proportion.

Keywords: Culture; Culture Points; Visibility; Identity.

\section{Introdução}

A cultura roraimense foi construída através de vários elementos da cultura brasileira. Sua identidade ainda é jovem devido o Estado estar próximo de completar apenas 28 anos de existência, fator determinante para considerar que Roraima está em pleno desenvolvimento no que diz respeito à sua identificação cultural e representatividade para o resto do país. Tendo em vista a importância da cultura para a consolidação de uma identidade e transformação social, este artigo teve como intuito verificar a visibilidade de iniciativas culturais que contribuem para este processo, neste caso tendo como objeto de estudo, os Pontos de Cultura, instalados em Boa Vista, coordenados pelo Governo do Estado. São entidades sem fins lucrativos que, através de suas atividades e ações transformam a sociedade, principalmente aqueles menos favorecidos.

A efetividade deste trabalho social só é possível a partir da devida prestação de contas sobre o que está sendo realizado por estes Pontos, e a visibilidade, seja ela em veículos de comunicação, redes sociais, portais eletrônicos, entre outras mídias, pode ser considerada uma espécie de vitrine para os gestores públicos e integrantes desses grupos, como também servir de inspiração para o surgimento de novos agentes e iniciativas culturais que fortaleçam mais e mais essa estrutura.

Porém, foi possível perceber que, em Boa Vista, as atividades realizadas por esses Pontos de Cultura recebem pouca importância, sendo que parte deles alcança visibilidade mínima na mídia local devido à falta de sensibilidade da Gestão Estadual, por parte da Secretaria Estadual de Cultura, em oferecer um melhor suporte aos Pontos, assim como em relação aos próprios Pontos, que em sua maioria enfrenta dificuldades em estabelecer um elo com a mídia e consequentemente com a sociedade.

Dentre as formas de comprovar esta questão, este artigo analisou um dos veículos de comunicação com maior expressividade em Roraima, o Jornal Folha de Boa Vista, que 
praticamente, todos os dias, publica matérias culturais. Foram verificadas as editorias de Cultura e Entretenimento do veículo, em todo o ano de 2015, onde foi possível perceber que a maioria dos Pontos é pouco divulgada. Embasado nesta problemática o presente artigo busca despertar uma reflexão em toda a sociedade sobre este tema, com foco nos gestores culturais envolvidos diretamente com a responsabilidade de comunicar a cultura, identidade e por serem peças fundamentais no processo de culturalização.

\section{Cultura e Identidade no Processo de Culturalização}

A cultura de forma geral não é simples de ser definida, tendo em vista a existência de valores particulares para cada aspecto, que pode mudar sua interpretação com as variáveis de cada localidade. Partindo desse princípio é possível afirmar que a mundo cultural tem envolvimento com o mundo natural, pois cada cultura possui uma leitura dos acontecimentos naturais. Segundo Levi-Strauss (apud MELLO 1986, p.397) “Cultura é este conjunto complexo que inclui conhecimento, crenças, arte, lei, costumes e várias outras aptidões e hábitos adquiridos pelo homem como membro de uma sociedade".

Desta forma, a cultura é produto resultante de um conjunto de significados e valores de grupos humanos, construindo-se ao longo de anos, situações, acontecimentos e comportamentos que se diferem de acordo com as características de cada povo. Este processo constante exerce grande influência na formação de identidades, já que a história da humanidade deixa claro que a evolução é resultado de um desenvolvimento conquistado de forma coletiva.

O cometido das identidades consiste em inscrever significados desde umas concreções retidas como representações. Tais significados são o que permite a alguém, um grupo ou instituição identificar e identificar-se, discernindo expressões identitárias que respondem a interesses de transcendência, fuição e consumo, particulares ou coletivos. (SILVEIRA, 2001, p.113).

A identidade cultural origina-se a partir dessas características peculiares que distinguem povos e nações até os dias atuais. É determinante quando se fala em valores, folclores e a diversidade de itens que repassam o reflexo da convivência em sociedade e as tradições de um determinado lugar. Assim como afirma Hall (2001, p.38) "a identidade é realmente algo formado, ao longo do tempo, através de processos inconscientes, e não algo inato, existente na consciência no momento do nascimento". São riquezas repassadas por gerações que dão significado ao sentimento de pertencimento que não somente a si próprio. 
Segundo Manuel Castells (2001, p.22) “entende-se por identidade a fonte de significado e experiência de um povo". Assim, a construção da identidade cultural pode ser compreendida como uma relação de identidade e diferença, onde os homens são influenciados pela sua pertença cultural. E através, tanto da cultura quanto da identidade cultural que é possível desenvolver e fortalecer as sociedades e comunidades através da culturalização ${ }^{2}$, que nada mais é que o processo de propagar a cultura.

\section{A Mídia como Ferramenta de Visibilidade}

A mídia de forma geral tem papel de difusão das informações por intermédio de todo o conjunto de meios de comunicação em massa (rádio, impressos, TV, cinema, extensivos e meios eletrônicos). A utilização dessas ferramentas de comunicação proporciona uma interação direta com o público-alvo, favorecendo diversos fatores sociais. Mattelart (2005, p.43) afirma: "A mídia configura-se como o palco onde estas identidades localizadas se tornam visíveis. Tendo como pressuposto que não há cultura sem mediação".

Dessa forma, a mídia tem destaque como instrumento fundamental na transformação da sociedade e da comunidade em geral, que com o avançar das tecnologias e das trocas de informações, entrelaçam-se de experiências e relações, fortificando a mídia como agente formador de opinião. Seu poder é perceptível nas relações sociais, desde o entretenimento até a mercantilidade da audiência, onde informação e publicidade atuam em sincronia intermediando aspectos mercadológicos, ideológicos e empresariais.

(...) segundo o entendimento de que cada povo tem direitos sobre sua cultura e de que sua adesão a essa cultura pode perder o vigor sob a influência da cultura industrializada difundida pelos meios de comunicação de massa. Por isso, é necessário adotar medidas para garantir do Estado o apoio econômico das tradições vinculadas à cultura tradicional e popular, tanto no interior das comunidades que as produzem quanto fora delas. (...) Deve-se sensibilizar a população para a importância da cultura tradicional e popular como elemento da identidade cultural. Para que se tome consciência do valor da cultura tradicional e popular e da necessidade de conservá-la, é essencial proceder a uma ampla difusão dos elementos que constituem esse patrimônio cultural. Numa difusão desse tipo, contudo, deve-se evitar toda deformação a fim de salvaguardar a integridade das tradições. (UNESCO, 1989. p.).

Atualmente, um dos principais setores para investimento; certamente variando com a localidade, bem como a forma de se comunicar. A mídia, enquanto formadora e

\footnotetext{
2 Ato ou efeito de culturalizar(se); processo de disponibilização ou de obtenção de cultura; Expansão e aprofundamento de uma cultura feito de modo institucionalizado (com recurso a meios de informação, ensino, etc.) CUlturalização in Dicionário da Língua Portuguesa com Acordo Ortográfico [em linha]. Porto: Porto Editora, 2003-2016.
} 
transformadora do cotidiano e comportamento do homem, promove ideias, tendências e modelos, lucrando com todas as faixas etárias de forma verbal e simbólica. Esta estrutura está, a cada dia, mais poderosa quando se trata da influência baseada em um sistema integrado de comunicação que tem papéis distintos dentro dos seus respectivos segmentos e, ao mesmo tempo, atuando em conjunto.

A atividade simbólica é característica fundamental da vida social, em igualdade de condições com a atividade produtiva, a coordenação dos indivíduos e a atividade coercitiva. Os indivíduos se ocupam constantemente com as atividades de expressão de si mesmos em formas simbólicas ou de interpretação das expressões usadas pelos outros; eles são continuamente envolvidos na comunicação uns com os outros e na troca de informações de conteúdo simbólico. (THOMPSON, 2012. p.42).

\section{Pontos de Cultura}

Os Pontos de Cultura são iniciativas regulamentadas pelo Ministério da Cultura $(\mathrm{MinC})^{3}$, através das Portarias $\mathrm{n}^{\circ} 156$ e $\mathrm{n}^{\circ}$ 82, de 06 de julho de 2004 e de 18 de maio de 2005. Foram criados através do Programa Mais Cultura e do Programa Cultura Viva, que contemplam todo o território nacional.

O Programa Mais Cultura foi implantado em outubro de 2008 e busca a ampla participação da sociedade civil e dos poderes públicos no processo de inclusão e integração de todos os segmentos sociais em Políticas Culturais que contribuem efetivamente para a redução da pobreza e desigualdade social.

Os Pontos ganharam ainda mais força em 22 de julho de 2014, data em que a presidente Dilma Rousseff sancionou a lei $\mathrm{n}^{\mathrm{o}}$ 13.018, instituindo a Política Nacional Cultura Viva (PNVC), fator que ofereceu à essas organizações mais autonomia e facilidade no desenvolvimento das atividades, incluindo a desburocratização do repasse dos recursos e consequente prestação de contas.

A escolha destes coletivos, fundações, cooperativas, sindicatos, dentre outras entidades sem fins lucrativos, para se tornarem Pontos de Cultura, é realizada através de edital lançado pela Gestão Estadual e/ou Municipal que, junto a uma Comissão Nacional analisa diversos critérios e condicionalidades necessárias para participação no Programa, que prevê, através de convênio, o repasse de recursos federais, divididos em parcelas, com contrapartida

3 Informações obtidas no site do Ministério da Cultura http://www.cultura.gov.br. 
do poder público, que servem de auxílio para elaboração e execução do Plano de Trabalho destas entidades.

Conforme meta do Plano Nacional de Cultura (PNC), instituído através da lei $\mathrm{n}^{\circ} 12.343 / 2010$, pelo menos 15 mil Pontos de Cultura espalhados pelo país devem receber fomentos até 2020. Dados da Secretaria da Cidadania e da Diversidade Cultural (SCDC) apontam que, desde 2004, já foram implantados pelo menos 4.500 Pontos em todo o Brasil e o objetivo é que até 2020, 15 mil estejam em pleno funcionamento.

\subsection{Os Pontos de Cultura em Roraima}

Em Roraima os Pontos de Cultura foram lançados em outubro de 2007, através de convênio n469, firmado pelo Governo do Estado, por meio da extinta Secretaria Estadual de Educação, Cultura e Desporto (Secd), hoje, Secretaria Estadual de Educação e Desporto (Seed), juntamente com o Ministério da Cultura. O edital de seleção para a implementação da Rede de Pontos de Cultura de Roraima ${ }^{4}$ foi publicado no dia 30 de agosto de 2012. O convênio corresponde ao valor total $\mathrm{R}$ \$ 1,9 milhão, sendo R \$ 1,3 milhão do MinC e R \$ 600 mil correspondentes à contrapartida do Governo.

Em 23 de janeiro de 2013 foi criada, por meio da lei $n^{\circ}$ 890, sancionada pelo Governador da época, José de Anchieta Júnior, a atual Secretaria Estadual de Cultura (Secult), a qual foi transferida a coordenação geral dos Pontos de Cultura de Roraima.

O Estado conta atualmente com um total de dez Pontos, sendo cinco na capital, Boa Vista e o restante no interior: Anarriê Amazônia (Boa Vista), Clássico para Todos (Boa Vista), Criart Teatral (Boa Vista), Usina Cultura (Boa Vista), Canoa Cultural (Boa Vista), Comunidade em Cena (Caracaraí), Artes e Danças Folclóricas (São Luiz do Anauá), Eco Cultura (Rorainópolis), Integração Cultural (São Luiz do Anauá) e Cultura para Quem Quer Cultura (São João da Baliza).

Conforme a Secult (2016) todos esses Pontos já receberam, entre 2009 e 2015, a primeira parcela do recurso, sendo que a maioria já está perto de receber a terceira parcela do

\footnotetext{
4 Informações obtidas com os próprios representantes dos Pontos de Cultura, em evento voltado à realização do repasse de recursos aos Pontos de Cultura, no dia 02/06/15, às 18h, no Salão Nobre do Palácio Senador Hélio Campos, Boa Vista, Roraima.
} 
convênio. O valor de cada repasse é de $\mathrm{R} \$ 60$ mil, totalizando a quantia de $\mathrm{R} \$ 180$ mil para cada Ponto de Cultura.

\subsection{Os Pontos de Cultura de Boa Vista}

Na capital de Roraima, cinco pontos desenvolvem atividades, nas suas mais diversas atribuições e linguagens artísticas, tendo como base o cumprimento das metas estabelecidas pelo PNC. O Ponto Anarriê Amazônia, por exemplo, tem como principal objetivo levar a cultura de Quadrilha Junina aos alunos de escolas da Rede Estadual de Ensino, por meio de aulas teóricas e práticas sobre o tema.

Paralelo a este trabalho, o Ponto oferece, oficinas de informática básica, literatura infanto-juvenil, "contação" de histórias e como parte do Plano de Trabalho está a formação do primeiro Coral Junino do Brasil.

Já o Criart Teatral, desenvolve ações de teatro e coral em uma escola da Rede Estadual de Ensino, atendendo através de oficinas mais de 150 crianças dos bairros Caranã, Cauamé e União, na potencialização de atividades artísticas que envolvem artes cênicas, música e novas mídias.

O Coletivo Canoa Cultural reúne artistas e diversos profissionais que atuam na transformação social da cultura, em artes integradas. Desde 2007 desenvolve diversos projetos musicais e de audiovisual, em sua maioria na capital, mas também com ações no interior do Estado, assim como em outros países, a exemplo da Venezuela.

O Usina Cultura trabalha a transversalidade da cultura, com atividades voltadas para o teatro, oferta de oficinas de múltiplas linguagens, audiovisual, fotografia, dança, além do Cineclube, que consiste na exibição de filmes. Por fim, o Clássico para Todos, uma orquestra criada por músicos brasileiros e venezuelanos, que busca levar a música de diversos gêneros aos mais diferentes públicos em todo o Estado de Roraima ${ }^{5}$.

\section{A Importância da Assessoria de Comunicação no Processo de Visibilidade dos Pontos de Cultura em Boa Vista}

5 Informações obtidas com os próprios representantes dos Pontos de Cultura, em evento voltado à realização do repasse de recursos aos Pontos de Cultura, no dia 02/06/15, às $18 \mathrm{~h}$, no Salão Nobre do Palácio Senador Hélio Campos, Boa Vista, Roraima. 
A Assessoria de Comunicação exerce um papel fundamental no tratamento das informações, visibilidade e eficácia das atividades desenvolvidas por um órgão, entidade, assim como ações de empresas públicas e privada.

\footnotetext{
À medida que as instituições foram se dando conta de que necessitavam do apoio da opinião pública para o pleno e satisfatório exercício de suas atividades, (...) a atividade de assessoria de imprensa [assim como a de comunicação] começou a ganhar impulso (...). (CRUZ, in FREITAS, LUCAS, 2002. p. 73)
}

Este trabalho, que ocorre de forma planejada e contínua, se torna ainda mais relevante quando o assunto é Cultura, visto que o segmento possui grande abrangência e representatividade na identidade de um povo, influenciando de diversas formas o cotidiano da população de determinada localidade.

É importante ressaltar que os Pontos de Cultura se encaixam no chamado "Terceiro Setor", que engloba associações, Organizações não Governamentais (ONG's), entidades sem fins lucrativos, dentre outros. Geralmente estas entidades, de caráter solidário, desenvolvem trabalhos de grande relevância social nas regiões onde atuam, fator que proporciona, quase de maneira natural, uma maior empatia por parte da população e da mídia, favorecendo a abertura para divulgação e consequente visibilidade do que se está sendo realizado por àquela determinada entidade.

Esta divulgação e visibilidade surte efeito positivo, segundo Ferrateto (2009, p.55) contribui para a legitimidade e continuidade do trabalho realizado por estas entidades. "É graças ao conhecimento de suas atividades pelo conjunto da sociedade que se dá, muitas vezes, a captação de recursos necessários à sua manutenção". Além disso, ações sociais que possuem grande valor no desenvolvimento do cidadão, geralmente são muito bem-vindas tanto pela população, quanto pela própria mídia, servindo inclusive de base para debates sobre problemas que afligem a sociedade e abrindo possibilidades para resolução destes gargalos.

O processo de desenvolvimento da cidadania inclui o amplo debate dos problemas sociais. Para isso, servem como instrumentos, entre outros, artigos, reportagens em jornais e revistas, entrevistas e debates em programas de rádio e televisão e chats informativos na internet. (FERRARETTO, 2009, p.56).

\subsection{A Assessoria de Comunicação da Secretaria de Cultura do Estado de Roraima e a Visibilidade dos Pontos de Cultura em Boa Vista}


A pesquisa, classificada como qualitativa e descritiva contou, por meio de entrevistas abertas, com a participação dos mais diversos personagens envolvidos neste tema, como o Governo do Estado, responsável pela coordenação de dez Pontos de Cultura que integram a Rede, em Roraima, com representantes dos próprios Pontos, instalados em Boa Vista/RR.

Para tomar conhecimento de que forma funciona o trabalho de divulgação das ações e atividades realizadas pelos Pontos de Cultura, foram realizadas entrevistas, conceituada por Richardson como:

O termo entrevista é construído a partir de duas palavras, entre e vista. Vista referese ao ato de ver, ter preocupação com algo. Entre indica a relação de lugar ou estado no espaço que separa duas pessoas ou coisas. Portanto, o termo entrevista refere-se ao ato de perceber realizado entre duas pessoas. (RICHARDSON, 1999, p 207).

Este artigo é fundamentado por meio de pesquisa aplicada, qualitativaque "não se preocupa com representatividade numérica, mas sim, com o aprofundamento da compreensão de um grupo social, de uma organização, etc." (Gerhardt\& Silveira, 2009. p.31) em busca de uma melhor compreensão dos fatos.Atrelada à técnica focalizada, que segundo Gil:

É bastante empregado em situações experimentais, com o objetivo de explorar a fundo alguma experiência vivida em condições precisas. Também é bastante utilizada com grupos de pessoas que passaram por uma experiência específica, como assistir a um filme, presenciar um acidente etc. (GIL, 2008, p. 48).

Essas entrevistas foram realizadas com integrantes dos seguintes Pontos: Anarriê Amazônia, Criart Teatral, Canoa Cultural e Usina Cultura, faltando somente conversar com o Ponto de Cultura Clássico para Todos, o qual o representante ${ }^{6}$, no período da pesquisa, estava a trabalho em outro país.

Destaca-se que todas as assessorias das mais diferentes pastas que compõem a estrutura da Gestão Estadual, inclusive a assessoria da Secretaria de Cultura, é subordinada à Secretaria de Comunicação do Governo do Estado (Secom). As pautas são produzidas pelos próprios assessores destas determinadas secretarias, porém para serem enviadas à imprensa precisam passar pela aprovação da Secom, responsável direto pelo envio dos materiais.

Em entrevista com a coordenadora estadual dos Pontos de Cultura, Jonayna Rodrigues, que assumiu esta função no início do mês de setembro de 2016, ela afirmou que,

6 O representante Carlos Mendes, no período da pesquisa, encontrava-se em Amsterdã, Holanda, a trabalho. 
consta no convênio este auxílio do Governo do Estado no que diz respeito à divulgação das ações realizadas por estas entidades e que a pasta cumpre este papel.

Foi assinado esse convênio junto ao Governo Federal e a partir daí foram inseridas as ações de um Plano de Trabalho comum de qualquer convênio. O Estado ficou com a parte de selecionar dez entidades sem fins lucrativos para estar executando as ações dos Pontos de Cultura e essa parte de divulgação ficou também por conta do Estado e dos Pontos que fossem contemplados com o recurso. É uma parceria junto aos Pontos. (RODRIGUES 2016, informação verbal) ${ }^{7}$.

Todos os Pontos de Cultura, ao receberem a primeira parcela do recurso, têm dentre as obrigações o destino de parte do incentivo à aquisição de equipamentos multimídia como, por exemplo, computadores, câmeras fotográficas, filmadoras, dentre outros itens importantes para trabalho de registro e divulgação das ações realizadas, o que não exime o poder público de fortalecer esta visibilidade com a cobertura das ações realizadas.

Em entrevista, por e-mail, com uma das representantes do Criart Teatral, Celis Regina Oliveira, integrante do Ponto há cinco anos, foi possível constatar os próprios integrantes realizam a cobertura e divulgação das ações, com auxílio mínimo por parte da Gestão Estadual.

A maioria da população do Estado nunca nem ouviu falar em Ponto de Cultura. Por isso, acredito que as atividades realizadas pelos Pontos de Cultura deveriam ser mais divulgadas pelo Governo do Estado. Entretanto, não ficamos de braços cruzados esperando que essa cobertura ocorra somente por parte do Governo. Enquanto executores do convênio, buscamos a imprensa para divulgarmos o trabalho desenvolvido. (OLIVEIRA, 2016, “apêndice I", grifo nosso).

A representante do Ponto Usina Cultura, Silmara Costa de Oliveira, também reforça esta falta de sensibilidade por parte da gestão Estadual no que diz respeito ao relacionamento com os Pontos e com a cultura em geral produzida em Roraima.

Não apenas as atividades dos Pontos, mas também nas ações da Rede Estadual, que é pulsante e potente. Em todo o Brasil a ação do Ponto de Cultura e a política pública Cultura Viva tem grande visibilidade e é carro chefe nas secretarias de cultura pelo Brasil. (OLIVEIRA, 2016, "apêndice I", grifo nosso).

Assim como o Criart, o Usina Cultura também realiza contato direto com a imprensa, principalmente com o envio de relise $e^{8}$ sobre as atividades realizadas, assim como convocando

7Informação obtida em entrevista concedida no dia 20/09/16, às 10h, no Gabinete da Secretaria Estadual de Cultura pela então coordenadora estadual dos Pontos de Cultura, Jonayna Rodrigues.

8 FERRARETTO, Elisa KopplinFerrareto. Assessoria de imprensa: teoria e prática / Elisa KoppliFerraretto, Luiz Artur Ferraretto - 5 ed. ver e atual - São Paulo: Summus, 2009. Material de divulgação produzido pela 
a imprensa para futuras ações. Já o integrante do Ponto de Cultura Anarriê Amazônia, Mário Moura relatou encontrar dificuldades em relação a este trabalho de divulgação, visto que segundo ele trata-se de um trabalho voluntário, reforçando a necessidade de um maior apoio da Gestão Estadual.

O perfil da nossa secretaria não é esse, ela não quer parceria. Quem faz realmente a divulgação dos Pontos De Cultura, os chamamentos na Rede de Pontos de Cultura, somos nós. A parceria que acontece é o repasse do recurso, está sendo a principal. (MOURA, 2016. Informação verbal) ${ }^{9}$.

Manoel Rolla é um dos integrantes mais antigos do Coletivo Canoa Cultural, que foi uma das últimas entidades a ingressar no convênio, recebendo a primeira parcela como Ponto de Cultura somente em junho de 2015, afirmou que trata-se de uma falha histórica

É uma falha histórica e não pontual, mas é uma grande falha. Não é somente com os Pontos de Cultura que isso acontece, mas sim com quase todas as atividades que a sociedade civil desempenha que o poder público não aproveita a oportunidade de divulgar as ações da melhor maneira possível. (ROLLA, 2016, "apêndice I", grifo nosso).

Manoel destaca que, entre os integrantes do Canoa Cultural, existe um jornalista formado que faz este trabalho de assessoria de imprensa junto à mídia roraimense, que para ele é fundamental para a promoção da visibilidade do Ponto.

Vemos a atividade da imprensa fundamental para mostramos os resultados dos eventos que produzimos. Um dos serviços que o próprio coletivo desenvolve desde o seu início é o de assessoria de comunicação. Temos uma jornalista formada cuidando das nossas redes sociais, canais nas mídias tradicionais e que informa a mídia tradicional através de um atualíssimo mailing list. (ROLLA, 2016, "apêndice I', grifo nosso).

\subsection{Análise Sobre a Visibilidade dos Pontos de Cultura no Jornal Folha de Boa Vista}

Ainda como forma de atestar a visibilidade dos Pontos de Cultura da capital, coordenados pelo Governo do Estado, esta pesquisa consistiu em analisar, no período de um ano (de janeiro a dezembro de 2015), as matérias veiculadas no jornal impresso Folha de Boa Vista, onde fala sobre as ações dos Pontos.

assessoria de imprensa e destinado aos veículos de comunicação. (...) De modo geral, a função básica do relise é levar às redações notícias que possam servir como material de apoio ou sugestão de pauta, propiciando solicitações de entrevistas ou de informações complementares.

9 Informação obtida em conversa por telefone no dia 20/09/16, às 21h07, com o coordenador do Ponto de Cultura Anarriê Amazônia, Mário Moura. 
O jornal foi escolhido por publicar, quase que diariamente, matérias culturais, além de ser considerado um dos meios de comunicação mais antigos do Estado e com maior alcance. A análise foi realizada com o auxílio da ferramenta de busca da FolhaWeb (www.folhabv.com.br), nos editorias: Cultura e Entretenimento, que replica o que é veiculado na versão impressa do veículo.

Conforme consta no Quadro I, é possível perceber que no período de um ano, composto por 365 (trezentos e sessenta e cinco) dias, as ações realizadas nos Pontos de Cultura em geral foram divulgadas apenas 28 (vinte e oito) vezes, sendo que e alguns meses não houveram veiculações de matérias relacionadas a estas entidades, a exemplo de janeiro, junho e julho. Além disso, ações de Pontos como Usina Cultura e Anarriê Amazônia sequer foram divulgadas na folhaweb no período da pesquisa.

Quadro 1 - veiculação de matérias na folhaweb no período de janeiro a dezembro de 2015.

\begin{tabular}{|l|c|c|c|c|c|c|}
\hline \multicolumn{7}{|c|}{ VEICULAÇÃO DE MATÉRIAS EM 2015 } \\
\hline MÊS & $\begin{array}{c}\text { CANOA } \\
\text { CULTURAL }\end{array}$ & $\begin{array}{c}\text { USINA DE } \\
\text { CULTURA }\end{array}$ & $\begin{array}{c}\text { CLÁSSICO } \\
\text { PARA } \\
\text { TODOS }\end{array}$ & $\begin{array}{c}\text { ANARRIÊ } \\
\text { AMAZÔNIA }\end{array}$ & $\begin{array}{c}\text { CRIART } \\
\text { TEATRAL }\end{array}$ & $\begin{array}{c}\text { N }{ }^{\circ} \text { DE } \\
\text { VEICULAÇÕES }\end{array}$ \\
\hline JAN & 0 & 0 & 0 & 0 & 0 & 0 \\
\hline FEV & $\mathbf{4}$ & 0 & 0 & 0 & 0 & $\mathbf{4}$ \\
\hline MAR & $\mathbf{5}$ & 0 & 0 & 0 & 0 & 5 \\
\hline ABR & 0 & 0 & 0 & 0 & $\mathbf{1}$ & $\mathbf{1}$ \\
\hline MAI & $\mathbf{1}$ & 0 & 0 & 0 & 0 & 0 \\
\hline JUN & 0 & 0 & 0 & 0 & 0 & 0 \\
\hline JUL & 0 & 0 & 0 & 0 & 0 & $\mathbf{3}$ \\
\hline AGO & $\mathbf{3}$ & 0 & 0 & 0 & 0 & $\mathbf{5}$ \\
\hline SET & $\mathbf{1}$ & 0 & 0 & 0 & 0 & $\mathbf{4}$ \\
\hline OUT & $\mathbf{3}$ & 0 & 0 & 0 & 0 & $\mathbf{3}$ \\
\hline NOV & $\mathbf{4}$ & 0 & 0 & 0 & 0 & $\mathbf{2}$ \\
\hline DEZ & $\mathbf{2}$ & 0 & $\mathbf{1}$ & 0 & & 0 \\
\hline
\end{tabular}

Fonte: www.folhaweb.com.br. DIAS (2016).

Destaca-se, ainda, que 23 (vinte e três) das 28 (vinte e oito) matérias publicadas no ano de 2015 são relacionadas ao Ponto de Cultura Canoa Cultural que, como o próprio representante afirma, o coletivo dispõe de um jornalista para a realização deste trabalho junto aos veículos de comunicação.

Em entrevista por e-mail com a jornalista das editorias de Cultura e Entretenimento da Folha de Boa Vista, Raísa Patrícia Souza de Carvalho, foi possível comprovar que a maioria das matérias, assim como as sugestões de pauta sobre as ações dos Pontos, é realizada pelas próprias entidades, com pouca participação do Governo do Estado. 
Geralmente as informações não passam por uma assessoria. Os próprios artistas entram em contato e fazem seus próprios releases para divulgação dos eventos. Quando existe alguma divulgação mínima, os assessores dão mais visibilidade às instituições e secretarias do que aos Pontos De Cultura. (CARVALHO, 2016, "apêndice II", grifo nosso) ${ }^{10}$.

A jornalista Inaê Brandão Lima, do Portal de Notícias G1 Roraima, também considera precária a divulgação destas entidades, principalmente por parte da Assessoria de Comunicação do Governo do Estado:

Creio que o governo do estado não divulga o suficiente os Pontos de Cultura de Roraima. Normalmente, quando é realizado algum tipo de evento por essas entidades, as próprias instituições divulgam seu material para a imprensa através de e-mail e das Redes Sociais. (LIMA, 2016, “apêndice II”, grifo nosso) ${ }^{11}$.

\section{Considerações Finais}

Os Pontos de Cultura possuem grande representatividade social e merecem sua devida importância e valorização, principalmente por parte de gestores estaduais e municipais, visto que são eles os responsáveis por coordenar e auxiliar, em diversos aspectos, as ações realizadas por estas entidades.

Em Roraima foi possível verificar que os Pontos de Cultura coordenados pelo Governo do Estado necessitam de maior suporte, no que diz respeito à divulgação das ações realizadas, no sentido de tornar pública e legítima a batalha diária dessas entidades em oferecer à população atividades que transformam vidas e, consequentemente, o meio em que esses personagens envolvidos estão inseridos. Além da preservação e construção de uma identidade cultural que passe para as futuras gerações; identidade essa, que pode gerar ainda mais movimentação econômica no Estado por meio do turismo, como ferramenta de apoio para a culturalização.

Fica reforçada nesta pesquisa, a necessidade de mais interesse, por parte da Gestão Estadual, em divulgar o que está sendo produzido pelos Pontos de Cultura, visto que são os gestores os responsáveis por elencar e direcionar o que é prioridade, não só em relação à visibilidade, mas à relevância, responsabilidade e compromisso em atuar em parceria com estas entidades.

10Entrevista concedida dia 05/09/16, por e-mail, pela jornalista de Cultura e Entretenimento, Raísa Patrícia Souza de Carvalho, do Jornal Folha de Boa Vista.

11 Entrevista concedida dia 08/09/16, por e-mail, pela jornalista Inaê Brandão Lima, do Portal de Notícias G1 RORAIMA <http://www.g1.com.br/rr >. 
Aos assessores, tanto da Secult, como da própria Secretaria de Comunicação, que possuem suporte de toda uma estrutura de Governo, com recursos, equipamentos e equipe capacitada, cabe também maior sensibilidade em explorar as atividades dos Pontos, estabelecer elos e contribuir, de maneira efetiva, para todo o esforço dessas entidades em transformar, através da cultura, a vida dos mais vulneráveis.

Sendo assim, este artigo deixa em aberto futuras discussões sobre o tema, em Roraima, tendo em vista as diversas dificuldades enfrentadas pelos Pontos de Cultura, no que diz respeito à articulação das ações junto à Gestão Estadual, assim como ruídos entre o Governo Estadual e o próprio Governo Federal.

\section{Referências}

BRANT, L. Mercado Cultural: panorama crítico e guia prático para gestão e captação de recursos. $4^{\mathrm{a}}$ ed. Ver e atual. São Paulo: Escrituras. Editora: Instituto Pensarte, 2004.

CARVALHO, RaísaPatrizia Souza de. RaísaPatrizia Souza de Carvalho: depoimento [set. 2016]. Entrevistador: Marcus Miranda: BOA VISTA-RR, 2016. E-mail e entrevista concedida para Artigo Científico.

CASTELLS, Manuel. O Poder da Identidade. São Paulo: Paz e Terra, 1999.

CERVO, Amado L., BERVIAN, Pedro A., SILVA, Roberto da. Metodologia Científica. São Paulo: Editora Pearson Prentice Hall, 2007.

COELHO, Teixeira. Dicionário Crítico de Política Cultural. São Paulo: Iluminuras/FAPESB, 2004.

CRUZ, Luiza. Pensamentos prático teóricos sobre um tema pragmático: a assessoria de imprensa e seu dia-a-dia. In: FREITAS, Ricardo Ferreira, LUCAS, Luciane.

Desafios contemporâneos em comunicação - perspectivas em relação públicas. SP: Summus, 2002. Coleção Novas Buscas em Comunicação, vol.65.

FAA/ESTÁCIO DE SÁ. Diretrizes Metodológicas da Faculdade Atual da Amazônia.

FEITOSA, Vera Cristina. Redação de textos. Boa Vista/RR: 2010.

FENAJ, Federação Nacional dos Jornalistas. Manual de Assessoria de Comunicação. 4. ed. Brasília/BR: Imprensa, 2007.

GIL, Antonio Carlos. Métodos e técnicas de pesquisa social - 6. ed. - São Paulo: Atlas, 2008.

KERLINGER, Fred N. Metodologia da Pesquisa em Ciências Sociais: um tratamento conceitual. São Paulo: EPU/EDUSP, 1980. 
LIMA, Inaê Brandão. Inaê Brandão Lima: depoimento [set. 2016]. Entrevistador: Marcus Miranda: BOA VISTA-RR, 2016. E-mail. Entrevista concedida para Artigo Científico.

MATTELART, A. 2005. Diversidade Cultural e mundialização. São Paulo: Parábola.

Métodos de pesquisa / [organizado por] Tatiana EngelGerhardt e Denise Tolfo Silveira: coordenado pela Universidade Aberta do Brasil - UAB/UFRGS e pelo Curso de Graduação Tecnológica - Planejamento e Gestão para o Desenvolvimento Rural da SEAD/UFRGS. Porto Alegre: Editora da UFRGS, 2009.

MINISTÉRIO DA CULTURA DO BRASIL. O Dia a Dia da Cultura. Disponível em: $<$ http://www.cultura.gov.br/o-dia-a-dia-da-cultura>. Acessado em: 25 ago. 2015.

MOURA, Mário. Mário Moura: depoimento [set. 2016]. Entrevistador: Marcus Miranda: BOA VISTA-RR, 2016. E-mail e verbal. Entrevista concedida para Artigo Científico.

NETO, Manuel Alberto RollaVilas-boas. Manuel Alberto Rola Vilas-boas Neto: depoimento [set. 2016]. Entrevistador: Marcus Miranda: BOA VISTA-RR, 2016.

E-mail e verbal. Entrevista concedida para Artigo Científico.

OLIVEIRA, Celis Regina. Celis Regina Oliveira: depoimento [set. 2016]. Entrevistador: Marcus Miranda: BOA VISTA-RR, 2016. E-mail e verbal. Entrevista concedida para Artigo Científico.

OLIVEIRA, Silmara Costa de. Silmara Costa de Oliveira: depoimento [set. 2016]. Entrevistador: Marcus Miranda: BOA VISTA-RR, 2016. E-mail e verbal. Entrevista concedida para Artigo Científico.

RICHARDSON, Roberto Jarry. Pesquisa Social: métodos e técnicas. 3. ed. São Paulo: Atlas, 1999.

RUBIM, L. Produção Cultural. In: RUBIM, L. Organização e Produção da Cultura. Salvador: EDUFBA; FACOM/CULT, 2005.

SILVEIRA, A.C.M. \& RONSINI, V.V.M. Representação e Identidade. Santa Maria: FACOS: FIPE: UFSM, 2001.

THOMPSON, John B. A Mídia e a Modernidade: Uma teoria social da mídia. 13. ed. Petrópolis, RJ: Vozes, 2012.

THROSBY, David. Economía y Cultura. Trad. De Cristina Piña y Maria Condor. 1. ed. Cambridge University Press, Madri, Espanha, 2001.

UNIVERSIDADE FEDERAL DE SANTA MARIA. Metodologia Científica. In: livro online em pdf. Disponível em: $<$ http://w3.ufsm.br/larp/media/metodologiacientifica.pdf $>$. Acesso em: 27 ago. 2015.

UNESCO E MINISTÉRIO DA CULTURA. Patrimônio imaterial: política e instrumentos de identificação, documentação e salvaguarda. Brasília - Recomendação Sobre a Salvaguarda da Cultura Tradicional e Popular,Paris, 1989. 

V. 04, $\mathrm{n}^{\circ}$ 02, maio-ago., 2018, artigo $\mathrm{n}^{\circ} 658$ | claec.org/relacult |e-ISSN: 2525-7870

VIEGAS, Waldyr. Fundamentos de Metodologia Científica. Brasília: Editora da UnB/Paralelo $15,1999$. 